Original Research Article

\title{
A retrospective study on drug utilization in patients with acute exacerbation of bronchial asthma in adults at tertiary teaching hospital in Bidar
}

\author{
Jyothi D. B.*, Gajanan P. Kulkarni
}

Department of Pharmacology, Associate professor, Bidar Institute of Medical Sciences, Bidar, Karnataka, India

Received: 07 December 2016 Accepted: 28 December 2016

*Correspondence to:

Dr. Jyothi D. B.,

Email:

premsagar467@gmail.com

Copyright: () the author(s), publisher and licensee Medip Academy. This is an openaccess article distributed under the terms of the Creative Commons Attribution NonCommercial License, which permits unrestricted noncommercial use, distribution, and reproduction in any medium, provided the original work is properly cited.

\begin{abstract}
Background: Drug utilization plays a role in helping the health care system to understand, interpret and improve the drug use and continuous quality improvement. It plays an essential part of pharmaco Epidemiological studies.

Methods: 100 prescriptions from patients with established diagnosis of acute exacerbation of Bronchial asthma were assessed from the Department of Pulmonary Medicine and the data gathered was analysed using MS Excel.

Results: Majority of the prescriptions irrespective of severity received inhalation $\beta 2$ agonist (formoterol) as a bronchodilator. Nebulization route was given for managing the acute exacerbations followed by inhalation route. Hydrocortisone was prescribed to all patients for managing acute Exacerbations. Montelukast was used an adjuvant therapy. Most of them were prescribed combination therapy. Theophylline was prescribed among all the methylxanthines.

Conclusions: $\beta 2$ agonists Combinations and corticosteroids are the most commonly prescribed combination drugs for asthma followed by methylxanthines. The most commonly prescribed asthmatic Medication in combination therapy was inhaled salbutamol with ipratropium followed by intravenous Hydrocortisone and oral Montelukast. The most commonly prescribed methylxanthine was intravenous Theophylline. Nebulization was preferred route to tackle the acute exacerbation of asthmatic symptoms.
\end{abstract}

Keywords: Bronchial asthma, Beta-2 agonist, Drug utilization studies

\section{INTRODUCTION}

WHO defines drug utilization research as "marketing, distribution, prescription and use of drugs in a society, with special emphasis on the resulting medical, social and economic consequences." DUR (drug utilization review) plays a key role in understanding the health care system, to improve and interpret the prescribing administration and to maintain the rational use of drugs which assist the physician's attitude in prescribing in accordance with predetermined standards by allocating them with feedback. It plays an important role in part of pharmacoepidemiological studies which provides a proper understanding with the usage pattern, quality, efficiency of drugs and its outcome.
Asthma is a syndrome characterized by chronic airway inflammation and increased airway hyper-responsiveness leading to symptoms of wheeze, cough, chest tightness and dyspnoea. It is characterized functionally by the presence of airflow obstruction which is variable over short periods of time, or is reversible with treatment. There are several inflammatory mediators that contribute the characteristic pathophysiological changes that lead to symptoms of asthma. Current estimates suggest that 300 million people world-wide suffer from asthma. ${ }^{3}$ In India it is estimated to be $15-20$ million, morbidity and mortality comprising about $3-11 \%$ of adults, $3-5 \%$ of paediatric population. ${ }^{4}$

According to GINA(Global Initiative for Asthma) guidelines, different group of drugs are suggested for the 
treatment of asthma that includes long and short acting beta2 agonist (salbutamol, salmeterol, formetorol), corticosteroids (fluticasone, prednisolone, bedesonide), xanthine derivatives (theophylline) and leukotriene receptor antagonist (montelukast). These drugs are either used alone or in combinations with antiasthmatic drugs

(5). Keeping this in the background the present study was to determine drug utilization pattern for managing acute exacerbation of bronchial asthma in adult population in a tertiary teaching hospital, BIDAR.

The aim was to evaluate drug utilization pattern in acute exacerbation of bronchial asthma among adults at a tertiary-care hospital, BIDAR.

\section{METHODS}

After taking approval from institutional Ethics Committee, a retrospective cross-sectional study was done analysing about 100 prescriptions. Patients were selected on the basis of inclusion and exclusion criteria i.e. patient aged more than 18 years diagnosed with acute exacerbation were included and patients having other respiratory problems like COPD, cardiac problems were excluded from this study.

Case records of the patients were assessed from the Department of pulmonary medicine at BRIMS teaching hospital, BIDAR. The data collection form provides the information regarding demographic details of the patient which includes age, sex, occupation, past history, family history and drug prescription which includes the drugs prescribed, route, dosage form, frequency. The percentage of all observed data was calculated.

\section{RESULTS}

Demographic analysis of data showed that there were $64 \%$ men and $36 \%$ women and maximum asthmatic patients were between 20-29 years of age group (Figure $1)$. The prescribed drugs are shown in the Table 1 . The results of this study showed that most of the patients received combination therapy rather than individual therapy. Majority of the patients received combination therapy of beta 2 agonist and corticosteroids via inhalational routes.

Table 1: Asthmatic medications.

\begin{tabular}{|ll|}
\hline Category & Drugs \\
\hline Beta2 agonists & Salbutamol, Formoterol \\
\hline Corticosteroids & $\begin{array}{l}\text { Hydrocortisone, Budesonide, } \\
\text { Methylprednisolone }\end{array}$ \\
\hline Methylxantines & Theophylline \\
\hline Anticholinergics & Ipatropium bromide \\
\hline Leukotriene modifiers & Montelukast \\
\hline Antihistamins & Levocitrizine \\
\hline
\end{tabular}

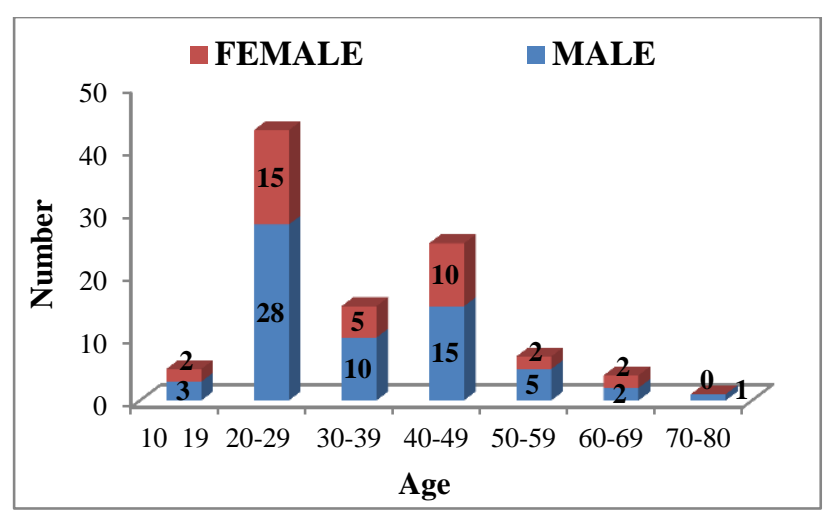

Figure 1: Demographic data of population under study.

From Figure 2 showed that salbutamol (beta 2 agonists) + ipratropium bromide (anti cholinergics) was most commonly used combinations as bronchodilator in $90 \%$ prescriptions followed by theophylline (methylxanthines) that was used in $50 \%$ of prescriptions. Corticosteroids which were in the form of hydrocortisone $(60 \%)$, budesonide $(52 \%)$, pre dnisolone $(5 \%)$ were depicted in 100 prescriptions. Majority of the patients received montelukast (leukotriene receptor antagonist) as an adjuvant treatment $(55 \%)$ for the control of asthmatic symptoms. For managing of acute exacerbations nebulization route was preferred.

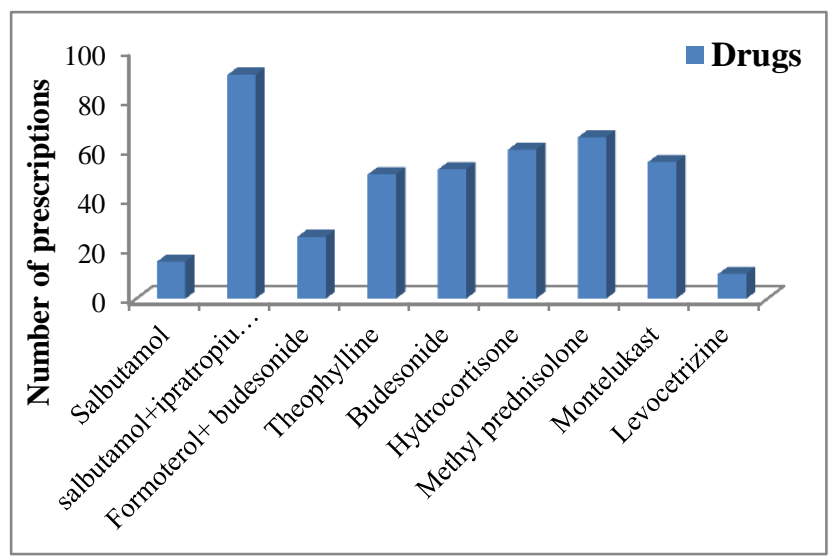

Figure 2: Prescribed asthmatic medications.

\section{DISCUSSION}

Prescription based study evaluates the rationality of the prescription. Rational prescribing practice guidelines have put forth to improve the standards of prescribing. ${ }^{6,7}$ In our study to manage acute exacerbations of asthmatic episodes nebulization route of drug delivery was the preferred route. Patients who are unable to use conventional inhaler, nebulizer is useful because there is little requirement of coordination from the patient as drug is inhaled through the face mask which colerates with normal tidal breathing. The main disadvantage of using nebulizer is lack of portability and long term commitment of maintenance. ${ }^{8}$ 
Inhalational therapy was however given to all patients who had treatment of acute exacerbation of bronchial asthma at the time of discharge. This is in accordance to the treatment guidelines i.e. inhalational therapy to be the first choice. Inhalational therapy provides less side effects, less dose is used and delivers more dug locally.,10 Effectiveness depends upon the technique used. Patient should be adequately instructed about the technique. A study in Cochrane stated that the compliance of the patient is decreased if failed to instruct the patients on how to use the inhalers. ${ }^{11}$

The most commonly prescribed inhaled bronchodilator was salbutamol with ipratropium bromide (90\%) followed by formoterol with budesonide (25\%) which was in coherence with study done in Bareilly which showed that inhaled salbutamol was received by $100 \%$ of patients irrespective of severity and study done in Malaysia in which salbutamol was most commonly prescribed. ${ }^{11,12}$ The reason for using short acting beta 2 agonist was because of its rapid onset and low cost. In our study injection hydrocortisone $(60 \%)$ was used to treat acute attack of asthma, it prevents the side effects of inhalational medication which causes irritation on respiratory tract. NAEPP guidelines recommends even oral route of corticosteroid for acute attack of asthma and reported to be as effective as intravenous route. ${ }^{13}$ Anticholinergics were commonly prescribed with combinations rather than individual therapy as they are preferred medication for COPD instead of asthma.

Intravenous theophylline was most commonly prescribed methylxanthines. However it is not as efficacious as doxophylline. However faiz et al, concluded that there is no significant difference in spirometric variables between doxophylline and theophylline. ${ }^{14}$

Corticosteroids constituted the most commonly used medication and intravenous was the preferred route, and was prescribed in $60 \%$ of the prescriptions, in contrast to study done by Sayadeda et al., corticosteroid was given by IV route in $100 \%$ cases of severe exacerbation and some cases of severe Exacerbation were also given MgSO4 (28.57\%) for additional bronchodilatation. ${ }^{12}$ Montelukast, a leukotriene receptor antagonist (55\%) was seen in most of the prescription as add-on therapy. It was prescribed as a fixed dose combination with levocetirizine $(36.8 \%)$ in a study done by Rajathilagam, et al. ${ }^{15}$ Limitations of our study were lack of follow up and cost effectiveness which should have been done. For higher authenticity more number of prescriptions should have been included in our study.

\section{CONCLUSION}

$\beta 2$ agonists Combinations and corticosteroids are the most commonly prescribed combination drugs for asthma followed by methylxanthines. The most commonly prescribed asthmatic medication in combination therapy was inhaled salbutamol with ipratropium followed by intravenous hydrocortisone and oral Montelukast. The most commonly prescribed methylxanthine was intravenous theophylline. Nebulization was preferred route to tackle the acute exacerbation of asthmatic symptoms.

\section{ACKNOWLEDGEMENTS}

I Thank (Dr Gajanan. P. Kulkarni- Associate professor BRIMS, BIDAR, Yogesh. B. Kamshette- Assistant professor BRIMS, BIDAR for the assistance. I would also like to show my gratitude to BIDAR INSTITUTE OF MEDICAL SCIENCES, BIDAR for supporting during the course of this research. Although any errors is my own and should not tarnish the reputations of these esteemed persons.

\section{Funding: No funding sources}

Conflict of interest: None declared

Ethical approval: The study was approved by the Institutional Ethics Committee

\section{REFERENCES}

1. Shimpi RD, Salunkhe PS, Bavaskar SR, Laddha GP, Kalam A, Patel AK. Drug utilization evaluation and prescription monitoring in asthmatic patients, Int. J. Pharm. Bio. Sci. 2012;2(1):117-12.

2. Varkey S, Sen S. Prescribing patterns of corticosteroids in Pulmonology Department, IJPTP. 2012;3:334-7.

3. Boon AN, Colledge NR, Brain R. Respiratory Disease. Walker Principles and practice of Medicine Davidson's 20 ${ }^{\text {th }}$ ed. Elseveir Limited; 2006:670.

4. Pinal DP, Patel RK, Patel NJ. Analysis of prescription pattern and drug utilization in asthma therapy, IRJP. 2012;3(7):257-60.

5. Sun HL, Kao YH, Chou MC, Lu TH, Lue KH. Differences in the prescription patterns of antiasthmatic medications for children by paediatricians, family physicians and physicians of other specialties, J. Formos. Med. Assoc. 2006;105(4):277-83.

6. International consensus report on diagnosis and treatment of asthma. National Heart, Lung, and Blood Institute, National Institutes of Health, Bethesda, Maryland, Eur. Respir. J. 1992;5(5):50911.

7. Ungar WJ, Coyte PC. Prospective study of the patient level cost of asthma care in children, Pediatr. Pulmonol. 2001;32:101-8.

8. Cochrane GM. Compliance and outcomes in patients with asthma, Drugs. 1996;52:12-9.

9. NIH, Guidelines for the Diagnosis and Management of Asthma, National Institutes of Health (NIH), Bethesda; 1997:41.

10. Reddel HK. Global Strategy for Asthma Management and Prevention, Global Initiative for Asthma; 2014;57-66.

11. Thamby SA, Juling $P$, Xin BTW, Jing NC. Retrospective studies on drug utilization patterns of 
asthmatics in a Government hospital in Kedah, Malaysia, Int. Curr. Pharm. J. 2012;1(11):353-60.

12. Sayadeda K, Ansari NA, Ahmed QS, Upadhyay P, Dey S, Madhwar A. Drug utilization study of antiasthmatic drugs in paediatric age group in a tertiary care teaching hospital, Bareilly, UP India, Int. J. Univ. Pharm. Biosci. 2013;2(3):145-56.

13. Drugs used in the treatment of asthma, in: J.U. Bradley, M.L. Lawrence (Eds.), Goodman and Gillman's The Pharmacological Basis of Therapeutics, Mc Graw Hill Publishers and Distributors, New York; 2006:717-773.

14. Akram MF, Nasiruddin M, Ahmad Z, Khan RA.
Doxofylline and theophylline: a comparative clinical study, J. Clin. Diagn. Res. 2012;6(10):1681-4.

15. Rajathilagam $T$, Sandozi $T$, Nageshwari AD, Paramesh P, Jamunarani R. Drug utilization study in bronchial asthma in a tertiary care hospital, Int. J. Pharm. Appl. 2012;3(2):297-305.

Cite this article as: Jyothi DB, Kulkarni GP. A retrospective study on drug utilization in patients with acute exacerbation of bronchial asthma in adults at tertiary teaching hospital in Bidar. Int J Basic Clin Pharmacol 2017;6:389-92. 